\title{
BMJ Open Patient-reported outcomes in paediatric cancer survivorship: a qualitative study to elicit the content from cancer survivors and caregivers
}

\author{
Jeanne A Pierzynski, ${ }^{1}$ Jennifer L Clegg, ${ }^{2}$ Jin-ah Sim, ${ }^{1}$ Christopher B Forrest, ${ }^{3}$ \\ Leslie L Robison, ${ }^{1}$ Melissa M Hudson, ${ }^{4}$ Justin N Baker, ${ }^{4}$ I-Chan Huang (1) ${ }^{1}$
}

To cite: Pierzynski JA, Clegg JL, Sim J, et al. Patient-reported outcomes in paediatric cancer survivorship: a qualitative study to elicit the content from cancer survivors and caregivers. BMJ Open 2020;10:e032414. doi:10.1136/ bmjopen-2019-032414

- Prepublication history and additional material for this paper are available online. To view these files, please visit the journal online (http://dx.doi. org/10.1136/bmjopen-2019032414).

Received 17 June 2019 Revised 26 March 2020 Accepted 30 March 2020

Check for updates

(c) Author(s) (or their employer(s)) 2020. Re-use permitted under CC BY-NC. No commercial re-use. See rights and permissions. Published by BMJ.

${ }^{1}$ Department of Epidemiology and Cancer Control, St Jude Children's Research Hospital, Memphis, Tennessee, USA

${ }^{2}$ Clinical Outcomes Solutions, Chicago, Illinois, USA

${ }^{3}$ Department of Pediatrics,

Children's Hospital of Philadelphia, Philadelphia, Pennsylvania, USA ${ }^{4}$ Department of Oncology, St Jude Children's Research Hospital, Memphis, Tennessee, USA

Correspondence to Dr I-Chan Huang; i-chan.huang@stjude.org

\section{ABSTRACT}

Objectives Content elucidation for patient-reported outcomes (PROs) in paediatric cancer survivorship is understudied. We aimed to compare differences in the contents of five PRO domains that are important to paediatric cancer survivorship through semistructured interviews with paediatric cancer survivors and caregivers, and identified new concepts that were not covered in the item banks of the Patient-Reported Outcomes Measurement Information System (PROMIS).

Design Semistructured interviews to collect qualitative PRO data from survivors and caregivers.

Setting A survivorship care clinic of a comprehensive cancer centre in the USA.

Participants The study included 51 survivors ( $<18$ years old) and 35 caregivers who completed interviews between August and December 2016. Content experts coded the transcribed interviews into 'meaningful concepts' per PROMIS item concepts and identified new concepts per a consensus. Frequencies of meaningful concepts used by survivors and caregivers were compared by Wilcoxon rank-sum test.

Results For pain and meaning and purpose, 'Hurt a lot' and 'Purpose in life' were top concepts for survivors and caregivers, respectively. For fatigue and psychological stress, 'Needed to sleep during the day'/'Trouble doing schoolwork' and 'Felt worried' were top concepts for survivors, and 'Felt tired' and 'Felt distress'/'Felt stressed' for caregivers. Survivors reported more physically relevant contents (eg, 'Hard to do sport/exercise'; 0.78 vs 0.23 , $p=0.007$ ) for pain, fatigue and stress, whereas caregivers used more emotionally relevant concepts (eg, 'Too tired to enjoy things I like to do'; 0.31 vs $0.05, p=0.025$ ). Both groups reported positive thoughts for meaning and purpose (eg, 'Have goals for myself'). One (psychological stress, meaning and purpose) to eleven (fatigue) new concepts were generated.

Conclusions Important PRO contents in the form of meaningful concepts raised by survivors and caregivers were different and new concepts emerged. PRO measures are warranted to include survivorship-specific items by accounting for the child's and the caregiver's viewpoints.
Strengths and limitations of this study

- Through semistructured interviews with survivors and caregivers, we investigated patient-reported outcome (PR0) contents for paediatric cancer survivors by referring to the contents of the PatientReported Outcomes Measurement Information System paediatric measures.

- This study used standard qualitative methods to collect, transcribe and code PRO interview data, followed by quantitative methods to compare frequencies/amounts of specific PRO concepts elicited by cancer survivors and caregivers.

- Although this study generated new PRO items based on emerging concepts related to paediatric cancer survivorship, psychometric properties and clinical validity of PRO items and measures were not evaluated, which is warranted in future research.

- Our study samples were recruited from a cancer centre alone and are not representative of all survivors of childhood cancer.

\section{INTRODUCTION}

The 5-year survival rate of children with cancer currently exceeds $80 \% .^{1}$ However, toxic treatment modalities can cause late effects, including chronic health conditions, ${ }^{2}{ }^{3}$ second cancers, ${ }^{4}{ }^{5}$ physical and neuropsychological deficits, ${ }^{6} 7$ poor patientreported outcomes (PROs), ${ }^{8} 9$ and premature mortality. ${ }^{10}{ }^{11}$ In contrast to conventional metrics (eg, laboratory tests, clinical evaluations and progression-free survival), PROs capture unique clinical endpoints important to survivors, such as symptoms and healthrelated quality of life (HRQOL). Systematic reviews report that physical, psychological and social PROs of child/adolescent cancer survivors overall are comparable with those of healthy counterparts but inferior if they experience late effects. ${ }^{12} 13$ Symptom complications and HRQOL deficits can worsen 
as survivors age, concurrent with the development of chronic health conditions. ${ }^{29}$

Obtaining PROs from child/adolescent survivors can be challenging, and caregivers are involved in this process if young age, and hearing, vision or cognitive deficits affect survivors' understanding of questions. ${ }^{14-16}$ Survivors' PROs as perceived by caregivers are highly valued in the shared decision-making process with clinicians, ${ }^{17}$ and viewpoints between survivors and caregivers may differ. ${ }^{18}$ How interview data collected from survivors and caregivers could be used to improve PRO content validity is unclear, and whether PRO concepts perceived by survivors and caregivers are sensational or supplemental is understudied. Using standard questionnaires, caregivers likely report significantly worse PRO scores for their childhood cancer survivors than survivors themselves. ${ }^{19}{ }^{20}$ In contrast to comparing PRO scores, eliciting PRO contents from survivors and caregivers offers indepth insights for survivorship care and represents a critical step towards improving the content validity of PRO measures. ${ }^{21}$

Among many paediatric PROs, content coverage of several domains important to survivorship outcomes and clinical application, such as pain, fatigue, psychological stress, stigma, and meaning and purpose, requires thorough investigations. Up to $60 \%$ of childhood cancer survivors experience fatigue ${ }^{22} 23$ and pain, ${ }^{24}$ respectively, and both are key drivers of poor HRQOL. ${ }^{25}$ Although paediatric cancer therapies and medical complications are stressful, ${ }^{26}$ previous studies largely focused on assessing self-perceived physical stress response in the context of environmental or internal challenges rather than psychological stress response. ${ }^{27}$ Besides experiencing psychological stress, survivors may also be stereotyped by peers or society. Evidence suggests that adults rate healthy children as more sociable and physically capable than children with cancer, suggesting the presence of stereotypes. ${ }^{28} \mathrm{It}$ remains unclear how cancer-related stigma or prejudice is perceived by survivors and caregivers. Despite troublesome late effects, some cancer survivors thrive. They feel that life has meaning and purpose and report positive life growth, which includes developing a sense of hopefulness, optimism and goal directedness. ${ }^{29}$ We chose these five PRO domains for investigations because they are vital to paediatric cancer survivorship, typically reflecting the common issues related to late effects of cancer therapies. ${ }^{18}$ Assessing these domains provides insightful clinical information as the goal of survivorship care is not merely decreasing the suffering (pain interference, fatigue, stress and stigma) but also achieving positive well-being (positive meaning and purpose) for paediatric cancer survivors.

Qualitative interviews provide a unique opportunity to explore PRO issues, especially when themes have not been fully understood. The merits of qualitative research, however, can be improved if data are abstracted, analysed or presented appropriately and meaningfully. Adopting the contents from an established PRO framework could help document and transfer raw interview data to a common metric for meaningful interpretation.

To advance PRO measures in paediatric cancer survivorship care and research, our first objective was to elicit and compare the concepts of five PRO domains (pain interference, fatigue, psychological stress, stigma, and meaning and purpose) from survivors and caregivers through semistructured interviews (SSIs). Previous paediatric cancer research has compared the choice of PRO items ${ }^{18}$ or tested PRO domain scores between cancer survivors and caregivers. ${ }^{19} 2030{ }^{31}$ However, the comparisons of PRO themes and concepts between survivors and caregivers derived from SSIs are understudied. Additionally, the methods used to quantify differences in qualitative data are limited. Through analysing PRO data from SSIs, we hypothesised that there would be differences between survivors and caregivers in elicited contents within the same PRO domains.

The second objective was to identify new PRO contents unique to paediatric cancer survivorship. We used the content (ie, item stem) from the extant paediatric item bank of the Patient-Reported Outcomes Measurement Information System (PROMIS), ${ }^{29}{ }^{32-35}$ the most comprehensive PRO assessment tools for children with different health conditions, as a framework to identify new concepts related to cancer survivorship. For children aged 8-17years, the PROMIS has developed different forms (item banks, short forms and computerised adaptive tests) to assess physical, mental and social aspects of PROs. ${ }^{36}$ PROs can be assessed through paediatric selfreports and parent-proxy versions, which have been evaluated with rigorous psychometric methods, including reliability, validity and responsiveness to change. . $^{37-41}$ However, measurement properties, especially content and clinical validity, of the PROMIS paediatric measures have not been systematically evaluated in childhood cancer survivors. We hypothesised that new concepts will emerge from the interviews, and the findings will benefit PRO assessments for paediatric cancer survivors by adding survivorship-relevant items to the current PRO measures.

\section{METHODS}

Design

This is a a qualitative interview study with paediatric cancer survivors and caregivers recruited from the After Completion of Therapy Clinic at St Jude Children's Research Hospital (St Jude) between August and December 2016. We followed the Standards for Reporting Qualitative Research to report our findings of qualitative data. ${ }^{42}$

\section{Participants and data collection}

We first identified eligible participants from a list of survivors scheduled for their annual follow-up and confirmed their eligibility through electronic medical records. We recruited survivors if they were 8-17 years of age at interview, at least 2 years off therapy, and at least 5 years from cancer diagnosis, and excluded if they had lower than a 
third-grade reading level, a general IQless than 70, or were identified with cancer recurrence and/or acute or lifethreatening conditions that require immediate medical attention. We recruited caregivers (family members who are the most knowledgeable of the survivor's health status and provide the direct care to the survivor) if they could speak and read English, and excluded individuals with an intellectual disability or communication problems. When eligible participants arrived at the clinic, clinical research associates enquired interest of participation, and obtained assent from survivors and consent from caregivers.

Because interviewing a PRO domain often takes approximately $20 \mathrm{~min}$ to complete by a child and approximately $15 \mathrm{~min}$ by a caregiver, we randomly assigned two (out of five) PRO domains to each survivor and two to three (out of five) PRO domains to each caregiver with the goal of completing an interview within $45 \mathrm{~min}$. Additionally, survivors and caregivers were assigned the domains randomly (vs exactly the same domains) because we are primarily interested in collecting comprehensive PRO contents from both survivors and caregivers rather than comparing the discordance of PROs between the paired survivors and caregivers. Researchers in the study eliminated potential bias during data collection, without any intervention or alteration.

Diagnostic information was abstracted from electronic medical records. Since some people may not be comfortable with reporting their socioeconomic status, especially personal or household incomes, we did not intend to collect socioeconomic data from participants. Given the significant associations of personal/household socioeconomic status (income, educational attainment and employment) with the level of area deprivation, we calculated the percentage of families falling below the poverty level where survivors and caregivers resided, per the US Census American Community Survey (www.census.gov), ${ }^{43}$ as a proxy of personal/household socioeconomic status.

\section{Interview procedure}

The research team developed five separate interview guides for pain interference, fatigue, psychological stress, stigma, and meaning and purpose domains (online supplementary tables 1-5), which were used by clinical research associates to conduct SSIs with study participants. Before we conducted formal interviews, we performed a pilot with four children and adolescents to understand the feasibility of the interview procedure. We specifically used debriefing techniques to identify potential problems related to ambiguity of interview questions/probes and burden that participants might perceive. The pilot only identified a few minor wording issues, suggesting the appropriateness of interview guides. The probes were created for each PRO domain to facilitate content elicitations.

Interviews were audio-recorded and transcribed verbatim. We transcribed the interview data from audio recordings, abstracted the sentences or paragraphs that were interpretable (defined as meaning units), and mapped the meaning units to analysable formats that represent the contents of PRO items in the PROMIS banks (defined as meaningful concepts). Items of the current PROMIS paediatric item banks, derived from qualitative or quantitative methods, ${ }^{29}{ }^{32-35}$ were used as a framework to map the meaningful concepts of survivors and their caregivers.

The process of creating meaning units and meaningful concepts has been emphasised in previous research. For example, the codes of WHO's International Classification of Functioning, Disability and Health - Children and Youth have been used as a framework to facilitate abstracting and mapping qualitative interview data. ${ }^{44-46}$ PROMIS has established rigorous standards to develop and validate paediatric PRO items, therefore serving a robust foundation for investigating PRO contents from our study participants. After the data were abstracted, we conducted statistical analyses to compare frequencies/amounts of qualitative information (in terms of meaningful concepts) reported by cancer survivors and caregivers.

Specifically, using the transcriptions, two content experts (JLC, CMJ) from two participating institutions independently reviewed the meaning units, compared the contents with the content of the PROMIS items, then assigned a meaning unit to a meaningful concept. Discrepancies were resolved by consensus between two senior investigators (CF, I-CH). New concepts emerged if the meaningful concepts derived from interviews with survivors and caregivers were not found in the item stems of the PROMIS item banks. The new concepts were determined based on the consensus of two content experts who compared each meaningful concept from the interviews and contents of the PROMIS item banks.

\section{Patient and public involvement}

Our research team designed the interview guides and probes to elicit the meanings and themes of PRO concepts from childhood cancer survivors and caregivers. It was not possible to involve patients or the public in the process of designing and conducting the interviews or reporting and disseminating the results. However, prior to the formal interviews, we conducted a pilot study with four children to debrief the content and meaning of the interview questions.

\section{Statistical analyses}

We conducted statistical analyses to compare the frequencies of meaningful concepts by each PRO domain between cancer survivors and caregivers. Since two and three domains were randomly assigned to respective survivors and caregivers for interviews, they were regarded as independent samples and independent tests were used. The Wilcoxon rank-sum test was used to compare the ordinal counts of elicited meaningful concepts between cancer survivors and caregivers, and the bootstrapping techniques (500 times) were applied to calculate 95\% CI for the estimated difference. The corresponding z-scores 


\begin{tabular}{|c|c|c|c|}
\hline \multirow[b]{2}{*}{ Characteristics } & \multirow{2}{*}{$\begin{array}{l}\begin{array}{l}\text { Survivors } \\
(\mathrm{n}=51)\end{array} \\
\text { Mean (SD) }\end{array}$} & \multirow{2}{*}{$\begin{array}{l}\text { Caregivers } \\
(\mathrm{n}=35)\end{array}$} & \multirow[b]{2}{*}{ P value* } \\
\hline & & & \\
\hline $\begin{array}{l}\text { Age at evaluation } \\
\text { (years) }\end{array}$ & $13.8(2.8)$ & $39.6(7.0)$ & $<0.001$ \\
\hline \multirow{2}{*}{$\begin{array}{l}\text { Families in the } \\
\text { community below } \\
\text { county-specific } \\
\text { poverty levels (\%) }\end{array}$} & $12.3(4.6)$ & $12.3(4.3)$ & 0.921 \\
\hline & n (\%) & n (\%) & $\mathbf{P}$ value \\
\hline \multicolumn{4}{|l|}{ Sex } \\
\hline Female & $31(61)$ & $32(91)$ & 0.002 \\
\hline Male & $20(39)$ & $3(9)$ & \\
\hline \multicolumn{4}{|l|}{ Race/ethnicity } \\
\hline White, non-Hispanic & $34(67)$ & $24(69)$ & 0.807 \\
\hline Black, non-Hispanic & $14(27)$ & $10(29)$ & \\
\hline Other & $3(6)$ & 1 (3) & \\
\hline \multicolumn{4}{|l|}{$\begin{array}{l}\text { Paediatric cancer } \\
\text { diagnosis* }\end{array}$} \\
\hline Non-CNS solid tumour & $22(42.3)$ & & NA \\
\hline Leukaemia & $17(32.7)$ & & \\
\hline CNS malignancy & 9 (17.3) & & \\
\hline Lymphoma & $4(7.7)$ & & \\
\hline
\end{tabular}

*Determined using Wilcoxon rank-sum tests.

†Determined using $\chi^{2}$ tests.

CNS, central nervous system; NA, not available.

with positive values indicate high frequency of meaningful concepts derived from cancer survivors compared with caregiver, and negative values indicate the opposite direction. Data were analysed using Stata V.14. Chord diagrams were generated for each PRO domain using the Circlize program in $\mathrm{R}^{47}$ to evaluate the pattern or frequency of meaningful concepts reported simultaneously by survivors and caregivers, respectively. Paired concepts used by $\geq 20 \%$ of survivors and caregivers, respectively, were used to generate diagrams.

\section{RESULTS}

\section{Characteristics of study participants}

Table 1 reports the characteristics of the participants. The study included 51 survivors and 35 caregivers. The mean ages of survivors and caregivers were 13.8 and 39.6 years. Most survivors $(58.8 \%)$ were white, non-Hispanic and were diagnosed with non-central nervous system solid tumour $(42.3 \%)$. Most caregivers were female $(90.9 \%)$ and white, non-Hispanic $(68.6 \%)$. The average per cent of families below the poverty line in communities where survivors and caregivers resided was $12 \%$.

\section{Meaning units and corresponding meaningful concepts}

Table 2 provides examples of meaning units and corresponding meaningful concepts. For pain interference, a survivor described that because of pain he/she "[couldn't] Play with [sibling's name] and [sibling's name]." This meaning unit was assigned the concept "Hard to do things with family'. For the fatigue domain, a survivor described how fatigue kept him/her from doing things with friends, such as "Probably making crafts or on the trampoline." This meaning unit was assigned the concept 'Hard to play or go out with friends'. For psychological stress, a survivor felt worried and described "That I was never going to make it." This meaning unit was assigned the concept 'Felt worried something bad would happen'. For the stigma domain, a survivor reported, "Um after the boy teased me, I tried not to like let it bother me but I was still, I mean I was kind of self-conscious about my scars back then and I still kind of am now." This meaning unit was assigned the concept "Unhappy how condition affected appearance'. For the meaning and purpose domain, a meaning unit from a survivor was "Because at St. Jude they helped me and I want to help other kids like me survive cancer and yeah." This meaning unit was given the new concept 'Want to help others'. Online supplementary table 6 shows that survivors reported a higher mean number of meaning units for all PRO domains (except for psychological stress), but comparable meaningful concepts compared with caregivers.

\section{Top meaningful concepts}

Table 3 reports the top meaningful concepts by individual PRO domains. The top meaningful concepts represent those concepts that were reported most frequently by survivors and caregivers (not accounting for the frequency count per participant). The most frequent pain interference concept reported by both survivors $(66 \%)$ and caregivers (92\%) was 'Hurt a lot'. For fatigue, 'Needed to sleep during the day' and 'Trouble doing schoolwork' were the most frequent concepts reported by survivors $(57 \%)$, and 'Felt tired' was the most frequent concept reported by caregivers $(77 \%)$. The ranking for concepts of psychological stress between survivors and caregivers was similar: 'Felt worried' was the most frequent concept reported by survivors (47\%), and 'Felt distressed' and 'Felt stressed' tied for the most frequent concept by caregivers $(64 \%)$. For stigma, 'Others my age made fun of me' was rated the top concept for survivors (50\%), and 'Others my age bullied me' was the top concept for caregivers $(75 \%)$. For meaning and purpose, 'Purpose in life' was rated the most frequent concept by both survivors $(70 \%)$ and caregivers $(69 \%)$.

\section{Number of meaningful concepts between survivors and caregivers}

Table 4 compares the number of meaningful concepts reported by survivors and caregivers. Overall, for the domains of pain interference, fatigue, and meaning and purpose, survivors reported more concepts than caregivers. For the pain interference domain, survivors reported the concepts 'Hard to sit' $(0.22$ vs 0 , $\mathrm{p}<0.001)$ and 'Hard to run' $(0.33$ vs $0, \mathrm{p}<0.001)$ more 
Table 2 Examples of meaning units derived from survivors and caregivers and corresponding meaningful concepts

\begin{tabular}{|c|c|c|c|}
\hline \multicolumn{2}{|l|}{ Survivors } & \multicolumn{2}{|l|}{ Caregivers } \\
\hline Meaning unit & Meaningful concept & Meaning unit & Meaningful concept \\
\hline \multicolumn{4}{|l|}{ Pain interference } \\
\hline \multicolumn{4}{|c|}{ Existing concepts in the PROMIS item banks } \\
\hline $\begin{array}{l}\text { "[couldn't] Play with [sibling's name] } \\
\text { and [sibling's name]." }\end{array}$ & $\begin{array}{l}\text { Hard to do things with } \\
\text { family. }\end{array}$ & $\begin{array}{l}\text { "The one where they blew up her bladder. Yeah } \\
\text { oh it was awful. She screamed a lot. Yeah had } \\
\text { a lot of pain with that and yeah so I warned her } \\
\text { about that because she had that done several } \\
\text { times." }\end{array}$ & Hurt a lot. \\
\hline $\begin{array}{l}\text { "Less focus." (other problems pain } \\
\text { caused) }\end{array}$ & Hard to pay attention. & $\begin{array}{l}\text { "He was just in a lot of pain from it and he had to } \\
\text { just-. I gave him medicine-he had to just chill out } \\
\text { for the whole day." }\end{array}$ & $\begin{array}{l}\text { Pain so bad had to take } \\
\text { medicine. }\end{array}$ \\
\hline
\end{tabular}

New concepts

"With the pain I was having I just felt Hard to eat. "Mhm, she didn't want anything to eat. I mean, Hard to eat. like I couldn't eat. I just wanted to lay down and go to sleep." she didn't want her cup or anything like that." (when she had pain)

"So it made stuff really hard like Hard to bathe/shower.
showers were hard because they hurt
so much."

Fatigue

Existing concepts in the PROMIS item banks

\begin{tabular}{|c|c|c|c|}
\hline $\begin{array}{l}\text { "Probably making crafts or on the } \\
\text { trampoline." (things can't do with } \\
\text { friends when tired) }\end{array}$ & $\begin{array}{l}\text { Hard to play or go out } \\
\text { with friends. }\end{array}$ & $\begin{array}{l}\text { "This past spring, she got really really tired and it } \\
\text { was after a lot of dance, a lot of rehearsals, lots } \\
\text { and lots and lots." }\end{array}$ & Felt tired. \\
\hline $\begin{array}{l}\text { "I always get home from school and } \\
\text { just go to sleep." }\end{array}$ & $\begin{array}{l}\text { Needed to sleep during } \\
\text { the day. }\end{array}$ & $\begin{array}{l}\text { "She'll probably fall asleep in the car on the way } \\
\text { home. When she gets home, she's just kind of } \\
\text { quiet in her room laying down." }\end{array}$ & $\begin{array}{l}\text { Needed to sleep during } \\
\text { the day. }\end{array}$ \\
\hline
\end{tabular}

\section{New concepts}

"Like if I'm wanting to walk around and Too tired to walk.

I'm just so tired, I have to like, I can't I

have to sit down and just chill out."

"Well, just that um by, I guess, by Too tired to move. getting tired, it's harder to move as fast and just be able to keep the speed up to get back, I guess."

Psychological stress

Existing concepts in the PROMIS item banks

\begin{tabular}{|c|c|c|c|}
\hline $\begin{array}{l}\text { "That I was never going to make } \\
\text { it." (thoughts when stressed during } \\
\text { sickness episode) }\end{array}$ & Felt worried. & $\begin{array}{l}\text { "[Child's] stress was more, I don't think so much } \\
\text { about doing the heart cath itself. It was that, 'I'm } \\
\text { not going to be able to possibly play football } \\
\text { anymore,' and that upset him." }\end{array}$ & Felt distressed. \\
\hline
\end{tabular}

\section{"Emotions... that I was feeling bad and Felt distressed.
"And it's just every little detail, he was worried
Felt worried. stuff like that." (how child felt when stressed)

"Sometimes she's just kind of ill and cranky and, Felt irritable.
um, don't mess with me type of attitude." (when
she is fatigued)
$\begin{aligned} & \text { "And then he'll fall asleep in class." (because } \quad \text { Fell asleep at school. } \\ & \text { child is tired) }\end{aligned}$

New concepts

"Faster heartbeat but that's just part of being stressed." (child's physical Physical experience of stress. about. Is my stance right, what's going on, l've hit before and now I can't, I'm not getting hits." experience of stress)

\section{"Her blood pressure will be high." (when child is Physical experience of stressed)

Stigma

Existing concepts in the PROMIS item banks

\begin{tabular}{|c|c|c|}
\hline $\begin{array}{l}\text { "I guess my perception on things } \\
\text { is different than other people's } \\
\text { perception. It's harder for me to do } \\
\text { some things than others." }\end{array}$ & $\begin{array}{l}\text { Felt different from } \\
\text { others my age. }\end{array}$ & $\begin{array}{l}\text { "Just would say, 'You are cross eyed or cock- } \\
\text { eyed' or 'You have a lazy eye.'” (how others } \\
\text { would bully child) }\end{array}$ \\
\hline
\end{tabular}

some things than others."
Others my age bullied me. 
Table 2 Continued

\begin{tabular}{|c|c|c|c|}
\hline \multicolumn{2}{|l|}{ Survivors } & \multicolumn{2}{|l|}{ Caregivers } \\
\hline Meaning unit & Meaningful concept & Meaning unit & Meaningful concept \\
\hline $\begin{array}{l}\text { "Um after the boy teased me, I } \\
\text { tried not to like let it bother me but }\end{array}$ & $\begin{array}{l}\text { Unhappy how condition } \\
\text { affected appearance. }\end{array}$ & $\begin{array}{l}\text { "Or they look at him and then their reaction on } \\
\text { their face, of, you know, disapproval." }\end{array}$ & $\begin{array}{l}\text { Others my age seemed } \\
\text { uncomfortable. }\end{array}$ \\
\hline
\end{tabular}

I was still, I mean I was kind of selfconscious about my scars back then and I still kind of am now."

\section{New concepts}

“Because they didn't quite understand Others didn't about it, or know they were being mean understand me. or anything." (Why did they tease you?)

\begin{abstract}
"He told his story in a poem and they then realized what happened, and people were in awe and they started treating him differently. And they realized that it was - that he had went through a lot of things, um, and that the cause of his, you know, his as far as his eye kind of looking the way it is. They didn't realize - they just didn't know the story and once they heard the story, they kind of changed their, um, tone as far as being mean."
\end{abstract}

Others treated me differently.

\footnotetext{
"It's just when you treat me differently I'm just like you know, don't do that like you don't have to change how you treat me because of my past so l'll just tell them like I'm fine now but after I tell them cancer, they're like oh my goodness. And I'm like it's okay you know. So I just do that, and like have yearly checkups and so it's all good now."
}

Others treated me differently.

Meaning and purpose

\section{Existing concepts in the PROMIS item banks}

"To have all as the rest of my life when Have goals for myself. I'm in school and have a really big house and being able to be a doctor at St. Jude." (important goals)

"Like, because when I had cancer and Pleased to be alive. stuff, I mean, I could've died."
"And so for her, to be able to give a person the nose that they want, or to help them look the same after a bad accident or something, for her, that's going to be perfect down the line. So right now, she's trying to line up the academics to make that happen." (child's goals)

"He just - he is here for a purpose to either bring our family close together or he is here to mentor or show someone else that, um, no matter what you go through, it could be worse. Or you know, it - it could always get better."

\section{New concepts}

\begin{tabular}{|c|c|c|c|}
\hline $\begin{array}{l}\text { "Because at St. Jude they helped me } \\
\text { and I want to help other kids like me } \\
\text { survive cancer and yeah." (why being } \\
\text { doctor a goal) }\end{array}$ & Want to help others. & $\begin{array}{l}\text { "She decided at one point in time that that's } \\
\text { what she wanted to do when she was older, } \\
\text { because she wanted to help kids that didn't have } \\
\text { anywhere to go really." }\end{array}$ & Want to help others. \\
\hline
\end{tabular}

PROMIS, Patient-Reported Outcomes Measurement Information System.

frequently than did caregivers. For the fatigue domain, survivors reported the concepts 'Kept me from having fun' (0.33 vs $0, p<0.001)$ and 'Got tired easily' (0.19 vs $0, \mathrm{p}<0.001)$ more frequently than did caregivers; however, the concept 'Body moves slower' was reported less often by survivors than did caregivers $(0.05$ vs 0.54 , $\mathrm{p}<0.001)$. For the psychological stress domain, survivors reported 'Worried something bad would happen' (0.37 vs $0, \mathrm{p}<0.001)$ and 'Felt scared' ( 0.37 vs $0, \mathrm{p}<0.001)$ more often than did caregivers. The concepts less frequently reported by survivors than caregivers under psychological stress included 'Felt like fighting' ( 0 vs $0.36, \mathrm{p}<0.001$ ) and 'Lost temper easily' ( 0 vs $0.36, \mathrm{p}=0.001$ ). For the stigma domain, 'Others my age avoided me' was reported more frequently by survivors than caregivers $(0.64$ vs 0 , $\mathrm{p}=0.001$ ), and 'Tended to blame myself for my problems' $(0.25$ vs $0, p=0.001)$ was endorsed more frequently by caregivers than survivors. For the meaning and purpose domain, survivors endorsed 'Expect to enjoy future life' $(0.20$ vs $0, p<0.001)$ more often than did caregivers; instead, survivors used 'Satisfied with purpose in life' $(0$ vs $0.25, \mathrm{p}<0.001)$ less often than did caregivers. Online supplementary figures 1-5 show the mean frequency of PRO contents reported by survivors and caregivers. Except for psychological stress, more than $50 \%$ of contents in the PROMIS measures were used by survivors 
Table 3 Top meaningful concepts reported by survivors and caregivers

\begin{tabular}{|c|c|c|c|}
\hline Survivors & Count (\%) & Caregivers & Count (\%) \\
\hline \multicolumn{4}{|l|}{ Pain interference* } \\
\hline Hurt a lot & $12(66)$ & Hurt a lot & $12(92)$ \\
\hline Hard to do sports/exercise & $9(50)$ & Pain so bad had to take medicine & $7(54)$ \\
\hline Hard to pay attention & $9(50)$ & $\begin{array}{l}\text { So much pain had to stop what he/she } \\
\text { was doing }\end{array}$ & $7(54)$ \\
\hline $\begin{array}{l}\text { So much pain had to stop what he/she was } \\
\text { doing }\end{array}$ & $8(44)$ & Felt grumpy & $6(46)$ \\
\hline Trouble moving around & $8(44)$ & Trouble moving around & $6(46)$ \\
\hline \multicolumn{4}{|l|}{ Fatigue $^{*}$} \\
\hline Needed to sleep during the day & $12(57)$ & Felt tired & $10(77)$ \\
\hline Trouble doing schoolwork & $12(57)$ & Felt irritable $\dagger$ & $8(62)$ \\
\hline Felt tired & $11(52)$ & Needed to sleep during the day & $8(62)$ \\
\hline Hard to pay attention & $10(48)$ & Did not have much energy & $7(54)$ \\
\hline Did not have much energy & $9(43)$ & Body moves slower† & $6(46)$ \\
\hline Felt irritable $†$ & $9(43)$ & & \\
\hline \multicolumn{4}{|l|}{ Psychological stress ${ }^{\star}$} \\
\hline Felt worried & $9(47)$ & Felt distressed & $9(64)$ \\
\hline Felt distressed & $7(37)$ & Felt stressed & $9(64)$ \\
\hline Felt stressed & $7(37)$ & Felt worried & $8(57)$ \\
\hline Physical experience of stress $\dagger$ & $6(32)$ & Felt under pressure & $7(50)$ \\
\hline Felt panicky & $5(26)$ & Felt frustrated & $6(43)$ \\
\hline \multicolumn{4}{|l|}{ Stigma* $\neq$} \\
\hline Others my age made fun of me & $7(50)$ & Others my age bullied me & $6(75)$ \\
\hline Felt different from others my age & $6(43)$ & Others my age made fun of me & $3(38)$ \\
\hline $\begin{array}{l}\text { Unhappy how condition affected } \\
\text { appearance }\end{array}$ & $6(43)$ & Others my age seemed uncomfortable & $3(38)$ \\
\hline Others treated me differently $\dagger$ & $5(36)$ & Others treated me differently $\dagger$ & $3(38)$ \\
\hline Felt left out of things & $4(29)$ & & \\
\hline Others my age bullied me & $4(29)$ & & \\
\hline \multicolumn{4}{|l|}{ Meaning and purpose ${ }^{*}$} \\
\hline Purpose in life & $14(70)$ & Purpose in life & $11(69)$ \\
\hline Meaning in life & $13(65)$ & Things I want to do in life & $11(69)$ \\
\hline Have goals for myself & $12(60)$ & Expect to have family in the future & $9(56)$ \\
\hline Expect to have job in the future & $9(45)$ & Expect to have job in the future & $9(56)$ \\
\hline Want to help others $\dagger$ & $9(45)$ & Meaning in life & $9(56)$ \\
\hline
\end{tabular}

*See online supplementary figures 1-5 for a full list of meaningful concepts for pain interference (33 concepts), fatigue (36 concepts), stress (37 concepts), stigma (17 concepts), and meaning and purpose (39 concepts).

†New concept generated from semistructured interviews.

fOnly top 4 concepts listed from caregivers because the fifth concept was a tie between three concepts.

and caregivers. Additionally, 11, 6 and 2 new concepts for fatigue, pain and stigma domains, respectively, were identified; one new concept for psychological stress and one new concept for meaning and purpose domains were identified. Based on the new concepts, 21 new items were created (see a list in online supplementary figure 1-5). In addition, there was no difference in the total meaningful concepts across four major cancer diagnoses (ie, central nervous system tumours, leukaemia, lymphoma and solid tumours) for all PRO domains reported by cancer survivors and caregivers, respectively, except for pain domain in cancer survivors (online supplementary table 7).

\section{Patterns of meaningful concepts concurrently reported}

Figures 1-5 show the pairs of concepts reported simultaneously by survivors and caregivers. In these figures, the 
Table 4 Comparison of numbers of meaningful concepts used by survivors and caregivers

Mean (SD) of frequency

Meaningful concepts

Pain interference

Hard to sit*

Hard to run

Needed help walking

Hard to do sports/exercise

Hard to pay attention

Felt angry

Hard to stay standing

Walked carefully

Pain so bad had to take medicine

Felt grumpy

Hurt a lot

Fatigue

Kept me from having fun

Got tired easily

Too tired to eat

Too tired to walk*

Too tired to talk

Too tired to read (for school)

Too tired to go up and down stairs

Trouble doing schoolwork

Felt weak

Too tired to think ${ }^{\star}$

Body moves slower

Fell asleep at schook

Too tired to enjoy things I like to do

Felt irritable*

Psychological stress

\section{Worried something bad would happen}

Felt scared

Too many things to do

Unable to remember answers, even for $0.16(0.37)$ questions I knew answer to

\begin{tabular}{|c|c|c|c|c|c|}
\hline Felt fearful & $0.11(0.32)$ & $0(0)$ & 3.23 & 0.49 to 1.98 & 0.001 \\
\hline Felt secure & $0.11(0.32)$ & $0(0)$ & 3.25 & 0.49 to 1.98 & 0.001 \\
\hline Felt in control of my life & $0.16(0.50)$ & $0(0)$ & 3.31 & 0.50 to 1.96 & 0.001 \\
\hline Felt panicky & $0.07(0.27)$ & $0(0)$ & 1.75 & -0.18 to 3.11 & 0.081 \\
\hline Felt like fighting & $0(0)$ & $0.36(0.63)$ & -4.23 & -3.58 to 1.31 & $<0.001$ \\
\hline Felt annoyed & $0(0)$ & $0.14(0.36)$ & -3.42 & -2.63 to 0.71 & 0.001 \\
\hline Thinking was slow & $0(0)$ & $0.14(0.53)$ & -3.17 & -1.88 to 0.44 & 0.002 \\
\hline Trouble concentrating & $0(0)$ & $0.14(0.36)$ & -3.24 & -2.69 to 0.66 & 0.001 \\
\hline
\end{tabular}

Continued

Wilcoxon rank-sum test

Normal

approximation

\begin{tabular}{|c|c|c|c|c|}
\hline Survivors & Caregivers & z-score & $95 \% \mathrm{Cl}$ & $P$ value \\
\hline$n=18$ & $n=13$ & & & \\
\hline $0.22(0.43)$ & $0(0)$ & 3.5 & 0.79 to 2.79 & $<0.001$ \\
\hline $0.33(0.69)$ & $0(0)$ & 3.85 & 0.88 to 2.70 & $<0.001$ \\
\hline $0.17(0.51)$ & $0(0)$ & 3.09 & 0.45 to 1.99 & 0.002 \\
\hline $0.78(0.94)$ & $0.23(0.83)$ & 2.7 & 0.60 to 3.80 & 0.007 \\
\hline $1.22(1.52)$ & $0.23(0.60)$ & 2.67 & 0.56 to 3.66 & 0.008 \\
\hline $0.50(0.71)$ & $0.01(0.28)$ & 2.61 & 0.49 to 3.44 & 0.009 \\
\hline $0.33(0.49)$ & $0.08(0.28)$ & 2.13 & 0.13 to 3.18 & 0.033 \\
\hline $0.33(0.14)$ & $0.08(0.28)$ & 1.69 & -0.22 to 3.02 & 0.09 \\
\hline $0.44(0.70)$ & 1.08 (1.19) & -1.61 & -3.38 to 0.33 & 0.107 \\
\hline $0.28(0.67)$ & $0.54(0.18)$ & -1.47 & -3.52 to 0.51 & 0.143 \\
\hline $1.39(0.31)$ & $2.00(0.41)$ & -1.33 & -3.01 to 0.57 & 0.182 \\
\hline $\mathrm{n}=21$ & $n=13$ & & & \\
\hline $0.33(0.58)$ & $0(0)$ & 4.14 & 1.10 to 3.08 & $<0.001$ \\
\hline $0.19(0.40)$ & $0(0)$ & 3.62 & 0.76 to 2.54 & $<0.001$ \\
\hline $0.14(0.36)$ & $0(0)$ & 3.17 & 0.54 to 2.28 & 0.002 \\
\hline $0.19(0.51)$ & $0(0)$ & 3.33 & 0.58 to 2.23 & 0.001 \\
\hline $0.19(0.51)$ & $0(0)$ & 3.22 & 0.55 to 2.29 & 0.001 \\
\hline $0.14(0.48)$ & $0(0)$ & 3.01 & 0.39 to 1.86 & 0.003 \\
\hline $0.10(0.30)$ & $0(0)$ & 3.15 & 0.43 to 1.83 & 0.002 \\
\hline 0.95 (1.16) & $0.23(0.44)$ & 2.42 & 0.40 to 3.78 & 0.016 \\
\hline $0.38(0.67)$ & $0.77(0.28)$ & 1.94 & -0.02 to 2.98 & 0.052 \\
\hline $0.21(0.41)$ & $0.08(0.28)$ & 1.87 & -0.07 to 2.95 & 0.061 \\
\hline $0.05(0.22)$ & $0.54(0.66)$ & -3.55 & -4.46 to 1.29 & $<0.001$ \\
\hline $0(0.0)$ & $0.08(0.28)$ & -2.98 & -2.11 to 0.43 & 0.003 \\
\hline $0.05(0.22)$ & $0.31(0.13)$ & -2.23 & -3.85 to 0.25 & 0.025 \\
\hline $1.00(1.30)$ & $1.85(1.57)$ & -1.62 & -3.40 to 0.33 & 0.106 \\
\hline$n=19$ & $n=14$ & & & \\
\hline $0.37(0.76)$ & $0(0)$ & 3.85 & 0.88 to 2.71 & $<0.001$ \\
\hline $0.37(0.83)$ & $0(0)$ & 3.87 & 0.89 to 2.71 & $<0.001$ \\
\hline $0.16(0.37)$ & $0(0)$ & 3.54 & 0.69 to 2.38 & $<0.001$ \\
\hline $0.16(0.37)$ & $0(0)$ & 3.51 & 0.68 to 2.39 & $<0.001$ \\
\hline
\end{tabular}

$0.11(0.32)$

$11(0.32)$

$0(0)$

0.50 to 1.96 
Table 4 Continued

\begin{tabular}{|c|c|c|c|c|c|}
\hline \multirow[b]{2}{*}{ Meaningful concepts } & \multicolumn{2}{|c|}{ Mean (SD) of frequency } & \multicolumn{3}{|c|}{ Wilcoxon rank-sum test } \\
\hline & Survivors & Caregivers & $\begin{array}{l}\text { Normal } \\
\text { approximation } \\
\text { z-score }\end{array}$ & $95 \% \mathrm{Cl}$ & $P$ value \\
\hline Small things upset me & $0(0)$ & $0.07(0.27)$ & -3.06 & -1.91 to 0.42 & 0.002 \\
\hline Felt nervous & $0(0)$ & $0.07(0.27)$ & -3.10 & -1.90 to 0.43 & 0.002 \\
\hline Too much going on & $0(0)$ & $0.07(0.27)$ & -2.98 & -1.93 to 0.40 & 0.003 \\
\hline Felt angry & $0.05(0.23)$ & $0.79(1.25)$ & -2.66 & -4.00 to 0.61 & 0.008 \\
\hline Felt under pressure & $0.37(1.01)$ & $1.00(1.24)$ & -1.79 & -3.69 to 0.17 & 0.073 \\
\hline Felt distressed & $0.63(0.96)$ & $1.29(1.27)$ & -1.62 & -3.58 to 0.34 & 0.104 \\
\hline Felt stressed & $0.47(0.77)$ & $0.79(0.70)$ & -1.61 & -3.43 to 0.37 & 0.108 \\
\hline Stigma & $\mathrm{n}=14$ & $\mathrm{n}=8$ & & & \\
\hline Others my age avoided me & $0.64(1.86)$ & $0(0)$ & 3.20 & 0.53 to 2.21 & 0.001 \\
\hline Felt different from others my age & $1.07(1.64)$ & $0.25(0.46)$ & 1.17 & -0.71 to 2.78 & 0.243 \\
\hline $\begin{array}{l}\text { Tended to blame myself for my } \\
\text { problems }\end{array}$ & $0(0)$ & $0.25(0.46)$ & -3.34 & -3.94 to 0.79 & 0.001 \\
\hline Others my age bullied me & $0.50(1.09)$ & $0.88(0.64)$ & -1.88 & -3.70 to 0.06 & 0.042 \\
\hline Others my age seemed uncomfortable & $0.29(1.07)$ & $0.63(0.92)$ & -1.54 & -3.58 to 0.43 & 0.125 \\
\hline Feel embarrassed about condition & $0.07(0.27)$ & $0.26(0.74)$ & -1.16 & -3.23 to 0.83 & 0.245 \\
\hline $\begin{array}{l}\text { Because of condition, others were } \\
\text { mean to me }\end{array}$ & $0.21(0.80)$ & $0.16(0.46)$ & -1.00 & -3.06 to 1.00 & 0.320 \\
\hline Meaning and purpose & $n=20$ & $\mathrm{n}=16$ & & & \\
\hline Expect to enjoy future life & $0.20(0.09)$ & $0(0)$ & 3.65 & 0.87 to 2.88 & $<0.001$ \\
\hline Expect good things to happen & $0.15(0.28)$ & $0(0)$ & 3.80 & 0.77 to 2.42 & $<0.001$ \\
\hline Life is filled with important things & $0.06(0.25)$ & $0(0)$ & 2.57 & 0.49 to 3.61 & 0.010 \\
\hline Have goals for myself & $1.05(1.32)$ & $0.31(0.48)$ & 2.31 & 0.30 to 3.67 & 0.021 \\
\hline Expect to achieve what I want in life & $0.3(0.47)$ & $0.06(0.25)$ & 2.12 & 0.13 to 3.40 & 0.034 \\
\hline Want to help others ${ }^{\star}$ & $0.9(1.25)$ & $0.25(0.58)$ & 2.04 & 0.07 to 3.47 & 0.041 \\
\hline Expect to succeed at what I try & $0.3(0.57)$ & $0.06(0.25)$ & 1.72 & -0.21 to 3.21 & 0.086 \\
\hline Things I need to do in life & $0.2(0.41)$ & $0.06(0.25)$ & 1.38 & -0.49 to 2.82 & 0.166 \\
\hline Satisfied with purpose in life & $0(0)$ & $0.25(0.57)$ & -3.54 & -3.09 to 0.89 & $<0.001$ \\
\hline Things I want to do in life & $0.25(0.44)$ & $0.88(0.72)$ & -3.33 & -4.43 to 1.15 & 0.001 \\
\hline Expect to have success in future & $0(0)$ & $0.13(0.34)$ & -3.23 & -2.58 to 0.63 & 0.001 \\
\hline Know where I am going in life & $0.10(0.31)$ & $0.44(0.51)$ & -2.53 & -4.06 to 0.52 & 0.011 \\
\hline Make plans for future & $0.05(0.22)$ & $0.25(0.45)$ & -1.91 & -3.44 to 0.05 & 0.056 \\
\hline Expect to have family in the future & $0.70(1.83)$ & $0.75(0.86)$ & -1.51 & -3.49 to 0.45 & 0.131 \\
\hline Life is filled with things that interest me & $0.25(0.55)$ & $0.56(0.72)$ & -1.52 & -3.47 to 0.44 & 0.129 \\
\hline Have goals for future & $0.25(0.55)$ & $0.50(0.63)$ & -1.57 & -3.24 to 0.36 & 0.116 \\
\hline
\end{tabular}

*New concepts generated from the semistructured interviews.

darker the colour of the line, the higher the frequency in reporting paired concepts, and the wider the arc on a circle the higher the frequency of reporting the concept. For all domains, the patterns for two simultaneous concepts were different between survivors and caregivers. For example, in the pain interference domain, 'Hurt a lot' was often reported together with 'Hard to do sports/exercise', 'Had to pay attention' and 'Felt sad' by survivors.
In contrast, 'Hurt a lot' was often reported together with 'Pain so bad had to take medicine', 'Had to stop what was doing' and 'Grumpy' by caregivers (figure 1). In the fatigue domain, 'Felt tired' was reported simultaneously with 'Felt irritable' by caregivers, but not reported by survivors (figure 2). When survivors felt stressed, caregivers perceived more psychological distress (eg, 'Felt distressed', 'Felt frustrated', 'Felt overwhelmed', 'Felt 


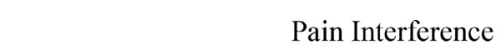

A

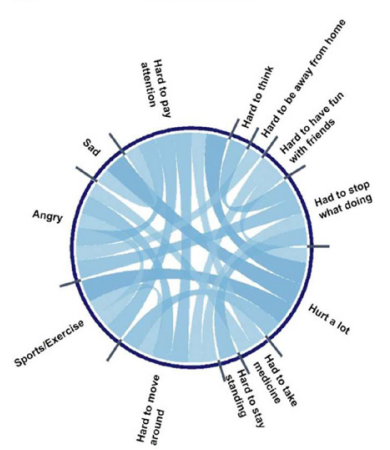

B

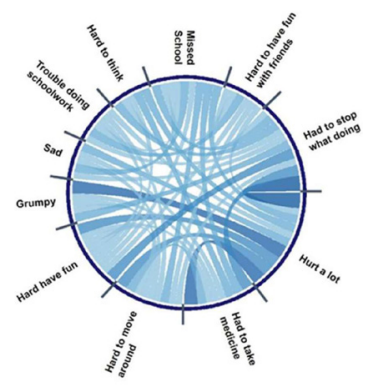

Figure 1 Patterns of meaningful concepts in pain interference concurrently reported by survivors and caregivers. Note: A meaningful concept was included in the chord diagram if the frequency of paired concepts reported by survivors and caregivers, respectively, was at least $20 \%$.

worried') than did survivors (eg, 'Felt worried') (figure 3). In the stigma domain, 'Others my age made fun of me' was paired with 'Others my age bullied me' for caregivers, but was not reported by survivors (figure 4). For the meaning and purpose domain, 'Expect to have job in the future' was frequently reported with 'Meaning in life' by survivors, but was commonly paired with 'Expect to have family in the future' by caregivers (figure 5).

\section{DISCUSSION}

This study applied novel methods to compare meaningful concepts of PROs elicited from qualitative interviews between childhood cancer survivors and caregivers. The results suggest that PRO issues relevant to survivorship (pain interference, fatigue, stigma, psychological stress, and meaning and purpose) concerned by survivors and caregivers were different. Using the PROMIS item banks as a framework, we identified new concepts from each PRO domain that were not captured by item stems in the current PROMIS banks. By extending previous research



Figure 2 Patterns of meaningful concepts in fatigue concurrently reported by survivors and caregivers. Note: A meaningful concept was included in the chord diagram if the frequency of paired concepts reported by survivors and caregivers, respectively, was at least $20 \%$.

Psychological Stress

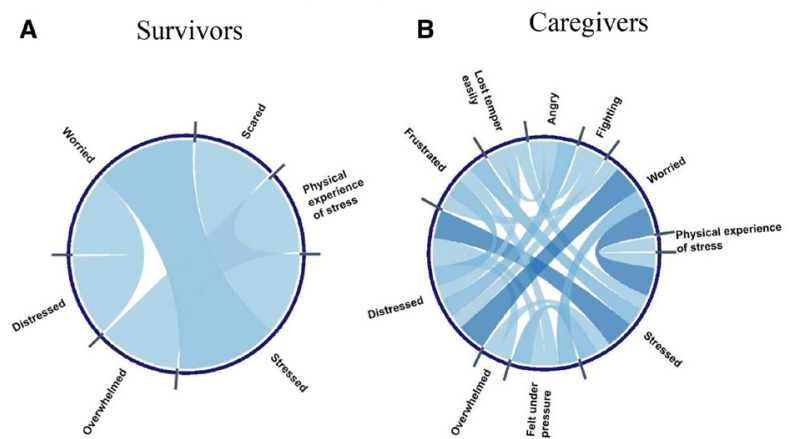

Figure 3 Patterns of meaningful concepts in psychological stress concurrently reported by survivors and caregivers. Note: A meaningful concept was included in the chord diagram if the frequency of paired concepts reported by survivors and caregivers, respectively, was at least $20 \%$.

that prioritised PRO items ${ }^{18}$ or compared discrepant PRO scores between survivors and caregivers, ${ }^{19} 203031$ this study provides a deeper understanding regarding the conceptualisation of PROs, which might benefit refining PRO measures for childhood cancer survivors and targeting specific PRO issues for interventions.

Pain and fatigue are the most common symptoms experienced by survivors of paediatric cancers. ${ }^{48} 49$ Without appropriate treatment, these symptoms may persist in adulthood and adversely affect daily functioning. ${ }^{90}$ We found several pain interference and fatigue meaningful concepts that were expressed more often by survivors than by caregivers. Intuitively, for survivors these concepts tended to be performance-based (eg, 'Hard to do sports/ exercise', 'Hard to pay attention' and 'Trouble doing schoolwork'). New concepts reported by survivors were physically relevant (eg, 'Hard to bathe/shower' and 'Hard to walk'), whereas those by caregivers were emotionally relevant (eg, 'Felt sad' and 'Felt irritated when tired'). These findings support that unique features of pain and fatigue reported by survivors and caregivers should be considered for inclusion into the extant PROMIS system.

Theoretically, psychological stress encompasses the emotional, cognitive and somatic reaction to stress. We
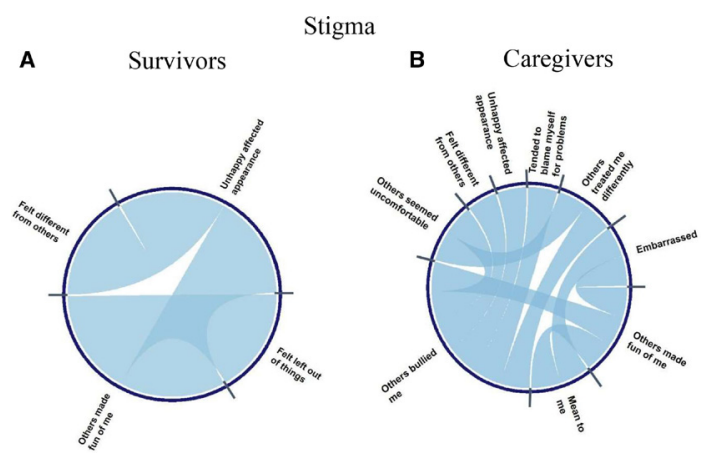

Figure 4 Patterns of meaningful concepts in stigma concurrently reported by survivors and caregivers. Note: A meaningful concept was included in the chord diagram if the frequency of paired concepts reported by survivors and caregivers, respectively, was at least $20 \%$. 
A Survivors

Meaning and Purpose
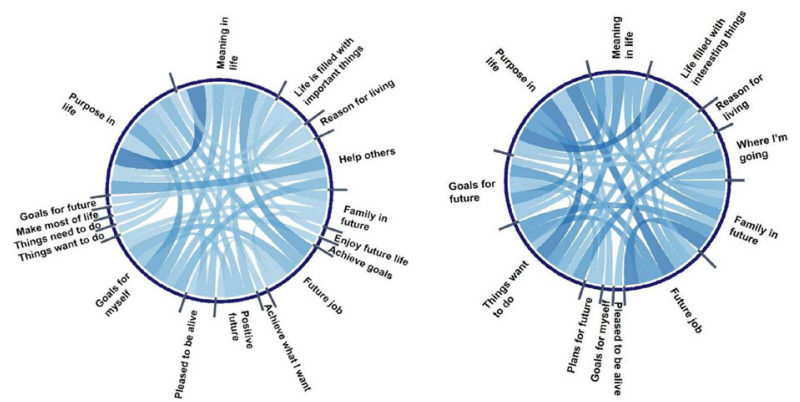

Figure 5 Patterns of meaningful concepts in meaning and purpose concurrently reported by survivors and caregivers. Note: A meaningful concept was included in the chord diagram if the frequency of paired concepts reported by survivors and caregivers, respectively, was at least $20 \%$.

found that survivors felt distressed about their current situation and worried that something bad would happen in the future. In contrast, caregivers expressed more aggressive psychological distress concepts than did survivors (eg, 'Felt like fighting', 'Lost temper easily', 'Felt angry'). This finding suggests that survivors with stress may display temper issues which caregivers observe. It is critical to screen stress issues (sources and types) during follow-up care because childhood cancer survivors who report stress with uncertainty and worry are at increased risk of alcohol abuse and/or smoking. ${ }^{51-53}$ Additionally, experiencing stress during childhood may lead to physiological dysfunction and chronic health diseases in adulthood. 5455

Individuals' perceptions about children with cancerrelated disabilities (eg, body image, neurocognitive deficits, and delays in social and academic skills) can lead to stereotypic reactions. In one study, friends and neighbours of children with chemotherapy-related hair loss endorsed embarrassment and discomfort, which survivors perceived as avoidance or unfriendliness. ${ }^{56}$ Stigmatisation perceived by both survivors and caregivers was related to psychological and behavioural problems (eg, 'Others my age made fun of me', 'Others my age bullied me', 'Others my age seemed uncomfortable', 'No one understands me'). This negative stigmatisation raises clinical concerns, as perceived discrimination in adolescents has been associated with an elevated risk of behavioural problems in the future (eg, cigarette/marijuana smoking, alcohol use or other drug abuse).$^{57}$ Also, perceived stigmatisation may inhibit adolescent cancer survivors from discussing follow-up care plans with caregivers or health professionals, which is a barrier to seeking survivorship care. ${ }^{58}$

Childhood cancer is a traumatic event, but some survivors embrace a new normal, life goals and life perspective, which result in greater appreciation for life, less worrying and increased empathy for others. ${ }^{59} 60$ Our study found that both survivors and caregivers valued 'Purpose in life' and 'Meaning in life' as top concepts. Survivors and caregivers also identified 'Have goals for myself' and 'Things
I want to do in life' as top concepts, which share a similar meaning. In our study, several interesting concepts not included in the extant PROMIS measures emerged (eg, 'Want to help others'). Survivors typically stated that they would like to become a medical doctor in the future to cure children with cancer. Surviving difficult therapies, coupled with encouragement and hopefulness from the healthcare team, has been reported to result in survivors developing a deeper appreciation for life and empathy. ${ }^{61}$

This study has important implications for survivorship care and research. The discrepancy in PRO concepts highly ranked by survivors and caregivers underscores the usefulness of collecting PROs from both groups. Collecting PROs from caregivers is not to substitute those from survivors, but rather to supplement clinically important PRO content not reported by survivors (eg, hostile behaviours related to stress). PROMIS possesses an advantage over other PRO measures because PROMIS measures, especially domainspecific item banks, were created to capture comprehensive PRO concepts for children with different health conditions. However, novel findings from our study suggested that the extant PROMIS paediatric measures may not comprehensively capture PROs relevant to paediatric cancer survivorship. Based on new concepts identified from qualitative interviews with cancer survivors and caregivers, we created 21 new PRO items corresponding to 21 new concepts $(11,6$, 2, 1 and 1 for fatigue, pain, stigma, psychological stress, and meaning and purpose domains). To evaluate measurement properties of these new concepts, future studies are needed to cocalibrate new items alongside extant PROMIS items on the established metric for dimensionality assessment, followed by testing clinical validity for survivor-specific short forms (ie, associations with clinically relevant variables including severity or a change of late adverse effects). Our approach is in line with renewed PRO measurement systems (eg, PROMIS ${ }^{62}$ and European Organisation for Research and Treatment of Cancer ${ }^{63}$ ) to improve content validity and measurement properties of the PRO measures.

In addition to improving $\mathrm{PRO}$ measures, a list of concepts created from this study will alert clinicians to explore potential PRO problems that at-risk survivors may experience (eg, high frequencies of pain interference among survivors of lymphoma and leukaemia vs other diagnoses) during the survivorship follow-up care, which can be followed with standard surveys or structured interviews to diagnose psychobehavioural problems. We encourage our oncology community to develop effective communication guidelines to assist clinicians in discussing PROs during clinical encounters.

This study has some limitations. First, we focused on survivors treated at a single institution, whose experience with PROs may be different from those at other institutions. However, our survivor group represents various cancer diagnoses, ages and races/ethnicities, and includes families residing in counties with community poverty levels similar to the national average $(11.0 \%) .{ }^{43}$ Second, due to a small sample size, we did not explore thematic differences across diagnoses or treatment modalities. Survivors who received 
more intensive modalities may have endorsed unique PRO concepts differing from those who received fewer intensive therapies. Third, we did not compare results between mothers and fathers, as most caregivers were mothers. Mothers may have more conservative perspectives on their child's health than do fathers. ${ }^{64}$

In conclusion, the use of qualitative methods showed that the content of five PROMIS domains may not fully capture the experiences of childhood cancer survivors. Moreover, PRO concepts generated from survivor and caregiver interviews are complementary. The creation of 21 new PRO items through interview data paves a foundation for future research to test measurement and clinical validity towards improving PRO measures for paediatric cancer survivorship.

\section{Twitter Jin-ah Sim @jinah7}

Acknowledgements The authors would like to thank Rachel M Keesey, RN, Ruth J Eliason, RN, Conor M Jones, BS, and Jennifer Q Lanctot, PhD, for data collection through semistructured interviews, transcription and/or analysis, and John $\mathrm{R}$ Brooke, PhD, for assistance with the chord diagram generation using $\mathrm{R}$.

Contributors JAP assisted in the assembly of data, data analysis and result interpretation, and drafted the manuscript. JLC assisted in the collection and assembly of data, data analysis and result interpretation. J-aS assisted in the data analysis and result interpretation, and drafted the manuscript. CBF conceptualised and designed the study, and assisted in data analysis and result interpretation. LLR and $\mathrm{MMH}$ provided administrative support and assisted in the assembly of data. JNB conceptualised and designed the study, and provided administrative support. $\mathrm{I}-\mathrm{CH}$ conceptualised and designed the study, provided administrative support, assisted in collection and assembly of data, data analysis and result interpretation, and drafted the manuscript. All authors approved the final manuscript as submitted and agree to be accountable for all aspects of the work.

Funding The research reported in this publication was supported by the National Institute of Arthritis and Musculoskeletal and Skin Diseases of the National Institutes of Health under award number U19AR069525, and the National Cancer Institute under award numbers U01CA195547 and P30CA021765-33. The content is solely the responsibility of the authors and does not necessarily represent the official views of the funding agencies.

Competing interests None declared.

Patient consent for publication Not required.

Ethics approval The assent/consent forms and the study protocol were approved by the St Jude Institutional Review Board.

Provenance and peer review Not commissioned; externally peer reviewed.

Data availability statement Data are available upon reasonable request.

Open access This is an open access article distributed in accordance with the Creative Commons Attribution Non Commercial (CC BY-NC 4.0) license, which permits others to distribute, remix, adapt, build upon this work non-commercially, and license their derivative works on different terms, provided the original work is properly cited, appropriate credit is given, any changes made indicated, and the use is non-commercial. See: http://creativecommons.org/licenses/by-nc/4.0/.

\section{ORCID iD}

I-Chan Huang http://orcid.org/0000-0002-1194-3923

\section{REFERENCES}

1 Robison LL, Hudson MM. Survivors of childhood and adolescent cancer: life-long risks and responsibilities. Nat Rev Cancer 2014;14:61-70.

2 Oeffinger KC, Mertens AC, Sklar CA, et al. Chronic health conditions in adult survivors of childhood cancer. N Engl J Med 2006;355:1572-82.

3 Hudson MM, Ness KK, Gurney JG, et al. Clinical ascertainment of health outcomes among adults treated for childhood cancer. JAMA 2013;309:2371-81.
4 Neglia JP, Friedman DL, Yasui Y, et al. Second malignant neoplasms in five-year survivors of childhood cancer: childhood cancer Survivor study. J Natl Cancer Inst 2001;93:618-29.

5 Choi DK, Helenowski I, Hijiya N. Secondary malignancies in pediatric cancer survivors: perspectives and review of the literature. Int $J$ Cancer 2014;135:1764-73.

6 Ness KK, Hudson MM, Ginsberg JP, et al. Physical performance limitations in the childhood cancer Survivor study cohort. JCO 2009;27:2382-9.

7 Krull KR, Hardy KK, Kahalley LS, et al. Neurocognitive outcomes and interventions in long-term survivors of childhood cancer. J Clin Oncol 2018;36:2181-9.

8 Zeltzer LK, Recklitis C, Buchbinder D, et al. Psychological status in childhood cancer survivors: a report from the childhood cancer Survivor study. J Clin Oncol 2009;27:2396-404.

9 Huang I-C, Brinkman TM, Kenzik K, et al. Association between the prevalence of symptoms and health-related quality of life in adult survivors of childhood cancer: a report from the ST Jude lifetime cohort study. J Clin Oncol 2013;31:4242-51.

10 Armstrong GT, Liu Q, Yasui Y, et al. Late mortality among 5-year survivors of childhood cancer: a summary from the childhood cancer Survivor study. J Clin Oncol 2009;27:2328-38.

11 Armstrong GT, Chen Y, Yasui Y, et al. Reduction in late mortality among 5-year survivors of childhood cancer. N Engl J Med 2016;374:833-42.

12 McDougall J, Tsonis M. Quality of life in survivors of childhood cancer: a systematic review of the literature (2001-2008). Support Care Cancer 2009;17:1231-46.

13 Klassen AF, Anthony SJ, Khan A, et al. Identifying determinants of quality of life of children with cancer and childhood cancer survivors: a systematic review. Support Care Cancer 2011;19:1275-87.

14 Eiser C, Morse R. Can parents rate their child's health-related quality of life? results of a systematic review. Qual Life Res 2001;10:347-57.

15 Matza LS, Patrick DL, Riley AW, et al. Pediatric patient-reported outcome instruments for research to support medical product labeling: report of the ISPOR pro good research practices for the assessment of children and adolescents Task force. Value Health 2013;16:461-79.

16 Addington-Hall J, Kalra L. Who should measure quality of life? BMJ 2001;322:1417-20.

17 Matza LS, Swensen AR, Flood EM, et al. Assessment of health-related quality of life in children: a review of conceptual, methodological, and regulatory issues. Value Health 2004;7:79-92.

18 Jones CM, Baker JN, Keesey RM, et al. Importance ratings on patient-reported outcome items for survivorship care: comparison between pediatric cancer survivors, parents, and clinicians. Qual Life Res 2018;27:1877-84.

19 Eiser C, Vance YH, Horne B, et al. The value of the PedsQLTM in assessing quality of life in survivors of childhood cancer. Child Care Health Dev 2003;29:95-102.

20 Huang I-C, Shenkman EA, Leite W, et al. Agreement was not found in adolescents' quality of life rated by parents and adolescents. J Clin Epidemiol 2009;62:337-46.

21 U.S. Department of Health and Human Services FDA Center for Drug Evaluation and Research, U.S. Department of Health and Human Services FDA Center for Biologics Evaluation and Research, U.S. Department of Health and Human Services FDA Center for Devices and Radiological Health, et al. Guidance for industry: patientreported outcome measures: use in medical product development to support labeling claims: draft guidance. Health Qual Life Outcomes 2006;4:79.

22 Poort H, Kaal SEJ, Knoop H, et al. Prevalence and impact of severe fatigue in adolescent and young adult cancer patients in comparison with population-based controls. Support Care Cancer 2017;25:2911-8.

23 Nowe E, Stöbel-Richter Y, Sender A, et al. Cancer-Related fatigue in adolescents and young adults: a systematic review of the literature. Crit Rev Oncol Hematol 2017;118:63-9.

24 Alberts NM, Gagnon MM, Stinson JN. Chronic pain in survivors of childhood cancer: a developmental model of pain across the cancer trajectory. Pain 2018;159:1916-1927.

25 Macartney G, VanDenKerkhof E, Harrison MB, et al. Symptom experience and quality of life in pediatric brain tumor survivors: a cross-sectional study. J Pain Symptom Manage 2014;48:957-67.

26 Sharp KMH, Lindwall JJ, Willard VW, et al. Cancer as a stressful life event: perceptions of children with cancer and their Peers. Cancer 2017;123:3385-93.

27 Bevans KB, Gardner W, Pajer K, et al. Qualitative development of the PROMIS(R) pediatric stress response item banks. J Pediatr Psychol 2013;38:173-91. 
28 Wiens BA, Gilbert BO. A reexamination of a childhood cancer stereotype. J Pediatr Psychol 2000;25:151-9.

29 Ravens-Sieberer U, Devine J, Bevans K, et al. Subjective well-being measures for children were developed within the PROMIS project: presentation of first results. J Clin Epidemiol 2014;67:207-18.

30 Russell KMW, Hudson M, Long A, et al. Assessment of health-related quality of life in children with cancer: consistency and agreement between parent and child reports. Cancer 2006;106:2267-74.

31 Parsons SK, Fairclough DL, Wang J, et al. Comparing longitudinal assessments of quality of life by patient and parent in newly diagnosed children with cancer: the value of both raters perspectives. Qual Life Res 2012;21:915-23.

32 Varni JW, Stucky BD, Thissen D, et al. Promis pediatric pain interference scale: an item response theory analysis of the pediatric pain item bank. J Pain 2010;11:1109-19.

33 Lai J-S, Stucky BD, Thissen D, et al. Development and psychometric properties of the PROMIS(®) pediatric fatigue item banks. Qual Life Res 2013;22:2417-27.

34 Bevans KB, Gardner W, Pajer KA, et al. Psychometric evaluation of the PROMIS $\otimes$ pediatric psychological and physical stress experiences measures. J Pediatr Psychol 2018;43:678-92.

35 Lai J-S, Nowinski CJ, Zelko F, et al. Validation of the Neuro-QoL measurement system in children with epilepsy. Epilepsy Behav 2015;46:209-14.

36 Cella D, Riley W, Stone A, et al. The patient-reported outcomes measurement information system (PROMIS) developed and tested its first wave of adult self-reported health outcome item banks: 20052008. J Clin Epidemiol 2010;63:1179-94.

37 DeWalt DA, Gross HE, Gipson DS, et al. PROMIS(®) pediatric selfreport scales distinguish subgroups of children within and across six common pediatric chronic health conditions. Qual Life Res 2015;24:2195-208

38 Quinn $\mathrm{H}$, Thissen D, Liu Y, et al. Using item response theory to enrich and expand the PROMIS $₫$ pediatric self report banks. Health Qual Life Outcomes 2014;12:160.

39 Varni JW, Magnus B, Stucky BD, et al. Psychometric properties of the PROMIS $\AA$ pediatric scales: precision, stability, and comparison of different scoring and administration options. Qual Life Res 2014:23:1233-43.

40 Irwin DE, Gross HE, Stucky BD, et al. Development of six PROMIS pediatrics proxy-report item banks. Health Qual Life Outcomes 2012;10:22

41 Varni JW, Thissen D, Stucky BD, et al. Item-level informant discrepancies between children and their parents on the PROMIS $\left({ }^{(}\right)$ pediatric scales. Qual Life Res 2015;24:1921-37.

42 O'Brien BC, Harris IB, Beckman TJ, et al. Standards for reporting qualitative research: a synthesis of recommendations. Acad Med 2014;89:1245-51.

43 U.S. Census Bureau. American community survey, 2012-2016 American community survey 5-year estimates. Available: http:// factfinder2.census.gov [Accessed 12 Nov 2018].

44 Klang Ibragimova N, Pless M, Adolfsson M, et al. Using content analysis to link texts on assessment and intervention to the International Classification of Functioning, Disability and Health - version for Children and Youth (ICF-CY). J Rehabil Med 2011;43:728-33.

45 Hwang A-W, Yen C-F, Liou T-H, et al. Development and validation of the ICF-CY-Based Functioning Scale of the Disability Evaluation System--Child Version in Taiwan. J Formos Med Assoc 2015;114:1170-80.

46 Güeita-Rodríguez J, Florencio LL, Arias-Buría JL, et al. Content comparison of aquatic therapy outcome measures for children with neuromuscular and neurodevelopmental disorders using the International classification of functioning, disability, and health. Int J Environ Res Public Health 2019;16. doi:10.3390/ijerph16214263. [Epub ahead of print: 02 Nov 2019].

47 Gu Z, Gu L, Eils R, et al. circlize implements and enhances circular visualization in R. Bioinformatics 2014;30:2811-2.

48 Meeske KA, Patel SK, Palmer SN, et al. Factors associated with health-related quality of life in pediatric cancer survivors. Pediatr Blood Cancer 2007:49:298-305.

49 Lu Q, Krull KR, Leisenring W, et al. Pain in long-term adult survivors of childhood cancers and their siblings: a report from the childhood cancer Survivor study. Pain 2011;152:2616-24.

50 Mulrooney DA, Ness KK, Neglia JP, et al. Fatigue and sleep disturbance in adult survivors of childhood cancer: a report from the childhood cancer Survivor study (CCSS). Sleep 2008;31:271-81.

51 Park EB, Emmons KM, Malloy NW, et al. A qualitative exploration of health perceptions and behaviors among adult survivors of childhood cancers. J Cancer Educ 2002;17:211-5.

52 Cox CL, McLaughlin RA, Steen BD, et al. Predicting and modifying substance use in childhood cancer survivors: application of a conceptual model. Oncol Nurs Forum 2006;33:51-60.

53 Lee Y-L, Gau B-S, Hsu W-M, et al. A model linking uncertainty, posttraumatic stress, and health behaviors in childhood cancer survivors. Oncol Nurs Forum 2009;36:E20-30.

54 Grant KE, Compas BE, Stuhlmacher AF, et al. Stressors and child and adolescent psychopathology: moving from markers to mechanisms of risk. Psychol Bull 2003;129:447-66.

55 Miller GE, Chen E, Parker KJ. Psychological stress in childhood and susceptibility to the chronic diseases of aging: moving toward a model of behavioral and biological mechanisms. Psychol Bull 2011:137:959-97.

56 Reid U. Stigma of hair loss after chemotherapy. Paediatr Nurs 1997:9:16-18.

57 Leventhal AM, Cho J, Andrabi N, et al. Association of reported concern about increasing societal discrimination with adverse behavioral health outcomes in late adolescence. JAMA Pediatr 2018;172:924-33.

58 Casillas J, Kahn KL, Doose M, et al. Transitioning childhood cancer survivors to adult-centered healthcare: insights from parents, adolescent, and young adult survivors. Psychooncology 2010;19:982-90.

59 Parry C. Embracing uncertainty: an exploration of the experiences of childhood cancer survivors. Qual Health Res 2003;13:227-46.

60 Mattsson E, Lindgren B, Von Essen L. Are there any positive consequences of childhood cancer? A review of the literature. Acta Oncol 2008;47:199-206.

61 Parry C, Chesler MA. Thematic evidence of psychosocial thriving in childhood cancer survivors. Qual Health Res 2005;15:1055-73.

62 Pilkonis PA, Choi SW, Reise SP, et al. Item banks for measuring emotional distress from the patient-reported outcomes measurement

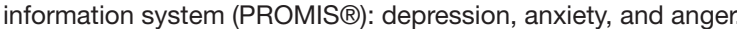
Assessment 2011;18:263-83.

63 Bell JA, Galaznik A, Pompilus F, et al. A pragmatic patient-reported outcome strategy for rare disease clinical trials: application of the EORTC item library to myelodysplastic syndromes, chronic myelomonocytic leukemia, and acute myeloid leukemia. J Patient Rep Outcomes 2019;3:35.

64 Hay DF, Pawlby S, Sharp D, et al. Parents' judgements about young children's problems: why mothers and fathers might disagree yet still predict later outcomes. J Child Psychol Psychiatry 1999;40:1249-58. 